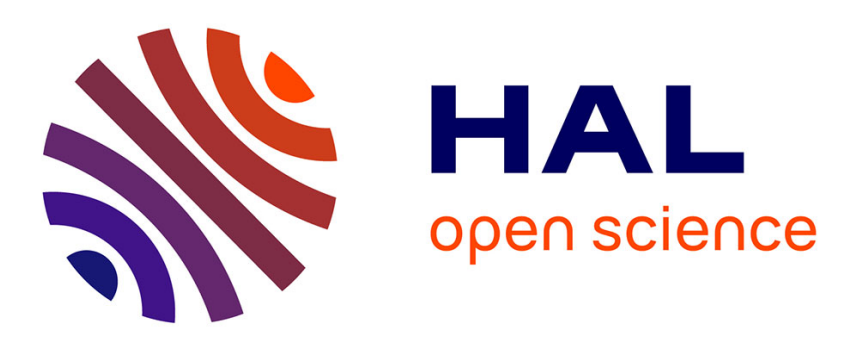

\title{
Influence of solar activity on hydrological processes
}

J. Pérez-Peraza, A. Leyva-Contreras, M. Valdés-Barrón, I. Libin, K.

Yudakhin, A. Jaani

\section{To cite this version:}

J. Pérez-Peraza, A. Leyva-Contreras, M. Valdés-Barrón, I. Libin, K. Yudakhin, et al.. Influence of solar activity on hydrological processes. Hydrology and Earth System Sciences Discussions, 2005, 2 (3), pp.605-637. hal-00301515

\section{HAL Id: hal-00301515 https://hal.science/hal-00301515}

Submitted on 11 May 2005

HAL is a multi-disciplinary open access archive for the deposit and dissemination of scientific research documents, whether they are published or not. The documents may come from teaching and research institutions in France or abroad, or from public or private research centers.
L'archive ouverte pluridisciplinaire HAL, est destinée au dépôt et à la diffusion de documents scientifiques de niveau recherche, publiés ou non, émanant des établissements d'enseignement et de recherche français ou étrangers, des laboratoires publics ou privés. 
Influence of solar activity on hydrological processes

\section{Influence of solar activity on hydrological processes}

J. Pérez-Peraza ${ }^{1}$, A. Leyva-Contreras ${ }^{1}$, M. Valdés-Barrón ${ }^{1}$, I. Libin ${ }^{2}$, K. Yudakhin ${ }^{2}$, and A. Jaani ${ }^{3}$

${ }^{1}$ Instituto de Geofísica, UNAM, C.U., Coyoacán, 04510, México D. F., Mexico

${ }^{2}$ IZMIRAN, Troitsk, Moscow, Region, 142092, Russia

${ }^{3}$ Estonian Meteorological and Hydrological Institute, Toom-Kooli 9, EE 0001, Tallinn, Estonia

Received: 4 March 2005 - Accepted: 29 March 2005 - Published: 11 May 2005

Correspondence to: J. Pérez-Peraza (perperaz@yahoo.com.mx)

(c) 2005 Author(s). This work is licensed under a Creative Commons License.

\section{J. Pérez-Peraza et al.}

\section{Title Page}

Abstract

Conclusions

Tables

14

4

Back

Full Screen / Esc
Introduction

References

Figures

$\rightarrow 1$

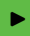

Close
Print Version

Interactive Discussion 


\section{Abstract}

The relationship between solar activity and the water volumes of lakes is searched here by means of correlational and spectral analysis methods. The level of two lakes, Pátzcuaro in México and Tchudskoye in Russia, together with solar activity indexes are 5 used for the analysis. It is found that the source of the oscillation mechanism of the level of those lakes is the solar activity cycle through its influence on the magnetosphere and the terrestrial atmosphere. The present study allows for the development of long-period prognostic of water volumes of big lakes.

\section{Introduction}

10 The complex phenomena of the field of Solar-Terrestrial Physics were described in the review of Pérez-Peraza (1990) and Pérez-Peraza et al. (1997). The problem of a possible relationship between the seasonal and the long period variations of different atmospheric, hydrologic and geophysical processes with heliophysical and cosmophysical processes has been discussed very often in the literature; for instance, Friis-

Christensen and Lassen (1992, 1995, 1996) and Baliunas and Soon (1995) have compeled more evidences than ever that solar activity has a direct link to Earthly weather. Since 1937 L. A. Chijzhevsky had argued about the primordial role of the sun within the group of phenomena and mechanisms which are now known as the field of SolarTerrestrial relationships (e.g. Chijzhevsky, 1976). At present there is no doubt that sphere are connected with heliophysical processes (Zatopek et al., 1976; Halenka, 1986). In particular, the atmospheric circulation, responsible for several hydrophysical processes, is subjected to the action of the cyclic variations of the solar activity (Zilhs et al., 1987). Such variations also control the geomagnetic activity and the temporal variations of cosmic rays intensity (e.g. Dorman et al., 1987a; Ariel et al., 1986; Xanthakis et al., 1981; Feynman, 1982; Chertkov, 1985). Consequently, a complex intercorrelation

\section{HESSD}

2, 605-637, 2005

Influence of solar activity on hydrological processes

J. Pérez-Peraza et al.

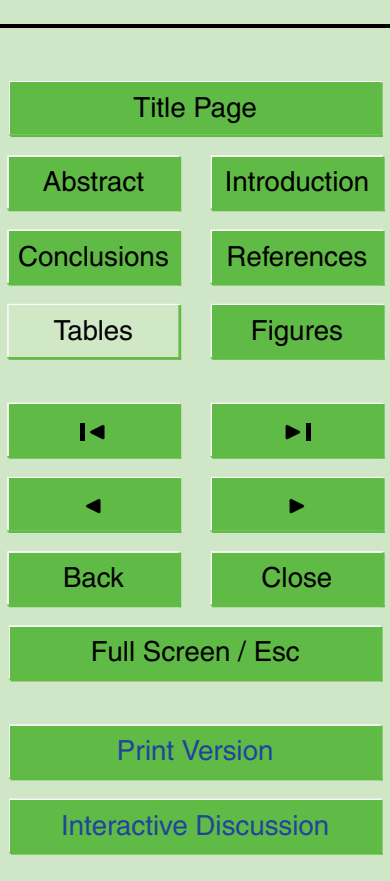

EGU 
of solar activity with all those mentioned phenomena (Dorman et al., 1987b; Novikov et al., 1984) including the processes which determine the water volumes of lakes (e.g. Jaani, 1973; Reap, 1981, 1986) is expected.

The goal of the present work is the search of correlational relationships with station-

5 ary and quasi-stationary dependencies between different hydrological, meteorological and cosmoheliophysical processes in order to make subsequent forecasts, as for instance, the average characteristics of the behavior of hydrological parameters (Janni, 1973; Libin et al., 1996). The existence of such relations are deduced from the mere comparison of the temporal variations of solar activity with: the volume of lakes (Jaani, 10 1973), the wind velocity in energetically active zones (Dorman et al., 1987a, b) and the intensity of cosmic rays at the earth surface (Xanthakis et al., 1981; Dorman et al., 1987b; Novikov et al., 1984). One of the processes that reflects the general state of the atmosphere, and hence the helioactivity behavior, is the cyclic variations of the volume of lakes (Jaani, 1973). The index to describe such a connection is the mean lake level 15 in a determined period, preferentially in large lakes without leakage. In the search of the mentioned intercorrelations, we use in the present work the annual mean values of: the sunspots surface $(S)$, the level of Lake Tchudskoye $(H)$ in the period 1885-1987, the frequency $(P)$ of strong winds in the Baltic Sea (Dorman et al., 1987a), the geomagnetic index $\left(K_{p}\right)$, and the cosmic ray intensity $(I)$ at station Kiel. The present study 20 is based on methods of spectral and correlational analysis with recurrent filtration of data (Key and Marpl, 1981).

\section{Description of lakes Pátzcuaro and Tchudskoye}

Lake Pátzcuaro is located between $19.5^{\circ} 32^{\prime}-19.5^{\circ} 34^{\prime}$ north latitude and $101.5^{\circ} 30^{\prime}-101.5^{\circ} 45^{\prime}$ west longitude, corresponding to the north-center part of the state of Michoacán, in México. The origin of the lake is connected to the transversal volcanic system that has been affected by a series of faults and sinks. The drainage pattern of this area is not integrated to any hydrological region, since the

HESSD

2, 605-637, 2005

\section{Influence of solar activity on hydrological processes}

J. Pérez-Peraza et al.

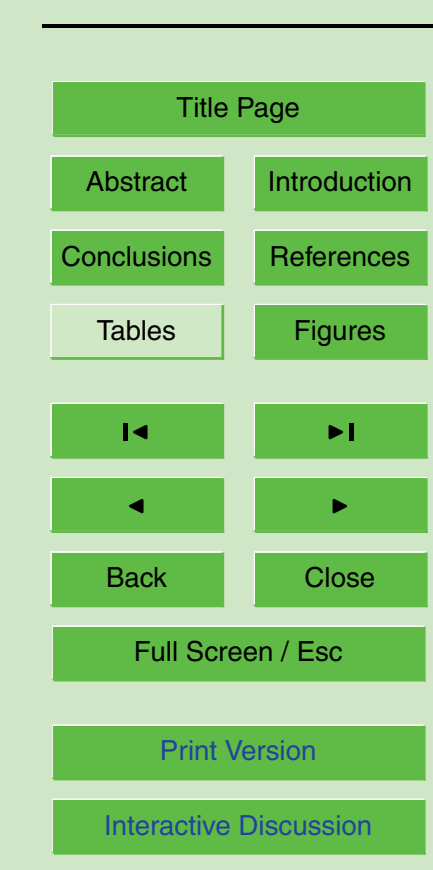

EGU 
leakages are often canalized or infiltrated in the land. However, it may be consider that it has a centripetal-radial drainage, because most of leakages converge toward the timber-roof depression; though the lake vessel is placed very near to the hydrological region No. 12 (Lerma-Chapala-Santiago) it is isolated from the large hydrological 5 systems of the country. This situation provokes important obstruct processes in the lake vessel because the recollection area has been subjected during long periods of time to erosive processes. The climate in the region is subhumid, with rains in summer, temperate, with an annual mean temperature oscillating between 16 and $18.5^{\circ} \mathrm{C}$, annual mean precipitation between 700 and $800 \mathrm{~mm}$ and average leakage to 10 the lake of $100-200 \mathrm{~mm}$.

Lake Tchudskoye is one of the largest lakes in Europe, occupying the fifth place in water mirror surface $(3600 \mathrm{~km})$ and the tenth place in Russia. The total surface of recollection including the lake is $47800 \mathrm{~km}$. The collectible zone extends in the meridional direction almost $370 \mathrm{~km}$, from $56^{\circ} 10^{\prime}$ up to $59^{\circ} 30^{\prime}$ north latitude, with a mean 15 width of $160 \mathrm{~km}$. The lake itself extends in the meridional direction almost $140 \mathrm{~km}$, and is located in the quadrant of $57^{\circ} 5^{\prime}-59^{\circ} 01^{\prime}$ north latitude and $26^{\circ} 57^{\prime}-28^{\circ} 10^{\prime}$ east longitude. The lake consists of three different parts, whose differences are of morphometric nature in their respective regimens, although they form a single water body (Jaani, 1987). According to the mean lake level assumed in this work, $30 \mathrm{~m}$ in the 20 Baltic system, the lake surface is $3555 \mathrm{~km}^{2}$ with a volume of $25.07 \mathrm{~km}^{3}$ (see The Lake Tchudskoye-Pskovskoe, 1983). This is a shallow lake, whose mean depth is $7.1 \mathrm{~m}$. To the lake disembogue about 240 Rivers and rivulets, among which the larger are: Belikaya (recollection surface of $\left.25200 \mathrm{~km}^{2}\right)$, Emaigi $\left(9960 \mathrm{~km}^{2}\right)$, Vykhandu $\left(1410 \mathrm{~km}^{2}\right)$ and Jzhelcha $\left(1220 \mathrm{~km}^{2}\right)$. The recollected water of these rivers reaching the lake from 25 the south (Lelikaya) and from the west (Emaigi and Vyklhandu) constitutes $80 \%$ of the lake recollection surface.

The regular investigations of Lake Tchudskoye were motivated by the big inundations $(1840,1844,1867)$ that provoke huge losses to the agriculture, as well as important depressions in the fishing volumes. In 1852, the leader of the Lake Commission Works,

\section{Influence of solar activity on hydrological processes}

J. Pérez-Peraza et al.

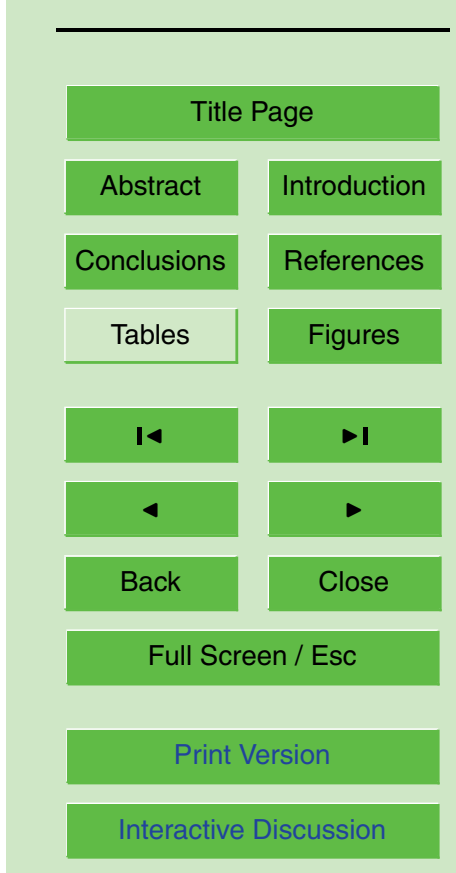


$\mathrm{K}$. Ber argued about the gradual elevation of the water level as a consequence of the economical activity in the recollection zone, basically due to the desiccation of forested zones, and to the channeling of cultivable lands. The same conclusions were reached by Gelmersen (1864). Afterward, a number of works were dedicated to the problems of 5 the depression of the level of the lake, and to the creation of a fluvial via between Lake Tchudskoye and the Baltic Sea (because due to the abundant water-falls and rapids, it is not possible to transit between the lake and the sea by the Narva River).

Schplinder and Zengbush (1896) analyzed the existing data up to that date, but found no evidence of the level elevation of the lake as was claimed by the general 10 consensus prevailing in those dates. Nevertheless, it was proposed by Kenig and Djzhivilov (1909) to reduce the lake level of $0.7 \mathrm{~m}$, to avoid inundations. In 1902 the expedition of Kenig installed the first observation sites for the measurements of the level of Lake Tchudskoye; among them, the station in the village of Vasknarva $(0.6 \mathrm{~km}$ down-current) is operating up to the present date.

In 1921, the hydrometeorological station of the lake was organized in the city of Mustvee, which until now is the main one furnishing a series of high quality observations with practically no interruptions. Using the correlation between the lake levels at Mustvee and Vasknarva, as well as those of the Emaigi River at the city of Tartu (where the measurements are going on since 1867) a data series of the level of Lake 20 Tchudskoye up to 1885 has been derived. In this way, the series of data of the annual lake level through 102 years consist of three parts:

1. Daily measurements in the city of Mustvee since march, 1921. The interruptions in 1937 (for hydraulic constructions) and in 1941 and 1944 (for the 2nd world war) were restorated with high preciseness by using observational data of other sites.

2. Monthly mean values of the lake level in the city of Mustvee, during the period 1903-1917, were determined by the correlation with the levels at the Vasknarva station.

\section{Influence of solar activity on hydrological processes}

J. Pérez-Peraza et al.

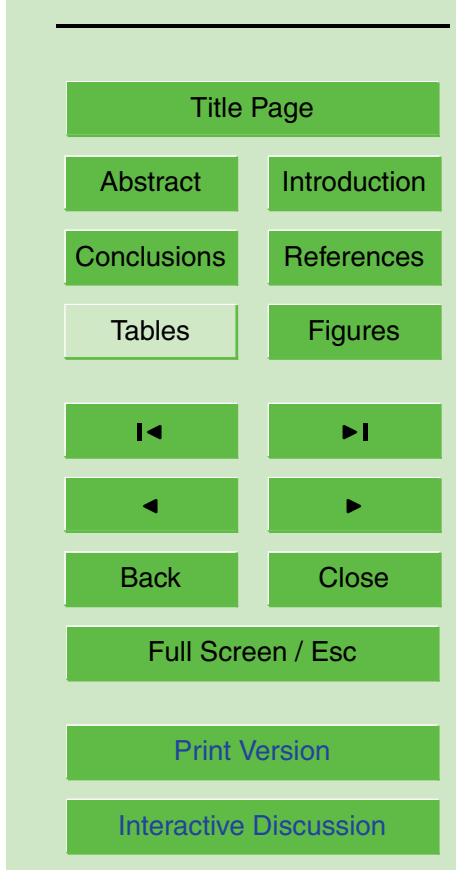

3. Annual mean level of the lake at Mustvee city in 1885-1902 and 1918-1920 was 609 
determined by the correlation with the levels of the Emaigi river at Tartu city during the summer. The correlation coefficient is $r=0.920 \pm 0.014$, so that the level of Lake Tchudskoye can be determined with a mean error $\delta= \pm 13 \mathrm{~cm}$. For an amplitude of the annual mean level at Mustvee of $149 \mathrm{~cm}$, the mean error of the estimated level is $9 \%$, such that the obtained data series may be considered as adequate for the analysis of the long period variations of the level of the lake.

As has been previously mentioned, 1840 and mainly 1844 were years of important inundations, and 1867 (and apparently also 1879) were years of high levels. In the period of instrumental observations, the highest levels were observed in 1924, 1928, 101957 and 1987. According to the existing data, the water level in 1844 was lower than in 1924 , and the later may be considered as the one with the highest water volume during all the period of quantitative data. In fact, this period contains all the amplitudes of oscillations of the annual mean level which is theoretically possible (L. Kullus, personal communication).

15 The problem of the level depression of the lake has been undertaken again after the unusual and catastrophic increase of the water volume in 1924: $775 \mathrm{~km}$ of land remained underneath the maximum lake level during 190 days. The possibility of a level reduction of Lake Tchudaskyoe was included in the peace agreement between Estonia and the Soviet Federal Socialist Republic of Russia in 1920: Estonia was allowed to reduce the level of the lake for about $30 \mathrm{~cm}$, by means of an artificial deviation of water. On the basis of a project dating from 1926, during the years 30's important hydrotechnic works were initiated at the Narva river birth and at the superior course of the river, with the aim of improving the leakage conditions and for a reduction of $30 \mathrm{~cm}$ of the level of the lake. The works were not concluded, so that the determination of the expected 25 effect is still an open problem.

In the last decades, the assumption of a progressive elevation of the lake level has been impugned. Rather, in spite of the short period of instrumental observations, the attention has been conducted to the study of the cyclic nature of the water volume variations of the lake. The presence of a cyclic behavior in the oscillations of the water

HESSD

2, 605-637, 2005

Influence of solar activity on hydrological processes

J. Pérez-Peraza et al.

Title Page

Abstract Introduction

Conclusions References

Tables Figures

14 $\rightarrow$

4

Back

Close

Full Screen / Esc

Print Version

Interactive Discussion 
volumes, and an anticorrelation of these cycles with the oscillations of solar activity (the maximum levels observed in periods of minimum solar activity, and conversely) has been established by Welner (1929), Velner (1940) and later by Eypre (1964, 1971).

A detailed analysis of the cyclic oscillations of Lake Tchudskoye was carried out by 5 Jaani (1973). Using the series of annual mean levels of the lake since 1885, and those of Lake Ladoga since 1859 (the holes in the data of this River were filled by A. Jaani): intersecular cycles with periods of 19-34 years (close to the so called Brikner cycles), were found as well as short period cycles with a mean extension of approximately 5.1 years. Furthermore, this author emitted the assumption about a relationship be10 tween the level of lakes and the 22 years cycle of the solar activity, and remarked a secular tendency to the reduction of such levels beginning from the years 20's. Quasibiannual cycles were not found in that study. As an intermediate mechanism A. Jaani analyzed the long period oscillations of the general atmospheric circulation (circulation of the Girs type) and found a similarity between the behavior of the level of Lake Tchudskoye and the index of the Atlantic circulation of Vitels; a certain tetra-compass activity in the level curve is explained by the influence of several phenomena of the solar activity on the atmospheric circulation processes. Reap (1981) carried out the spectral analysis of the same series, detaching cycles (in years) of 6.1-6.4, 10-11 and 80-90, whereas in the series of floods of the Neva river detache cycles of 5.1 years (not very well defined), 6.1-6.3, 10.5-11 and 29.3 years. This author emphasizes (based on the work of Smirnov (1975) that in the case of the floods of the rivers of the north-east zone of the European territory of Russia, the minimum of the 10-11 year cycles is observed 1 to 3 years after the maximum of solar activity, while the maximum of the river floods occur 2 to 4 years before the maximum of solar activity.

The out of phase situation (here after designated as "dephasage") of different processes are also observed in the study of correlations between meteorological phenomena and solar activity, with different shift magnitudes in different periods of the solar cycle; according to Gulinsky et al. (1988) such a magnitude is higher in the descending period of solar activity. The study of the "dephasage" between the atmospheric proper-

HESSD

2, 605-637, 2005

\section{Influence of solar activity on hydrological processes}

J. Pérez-Peraza et al.

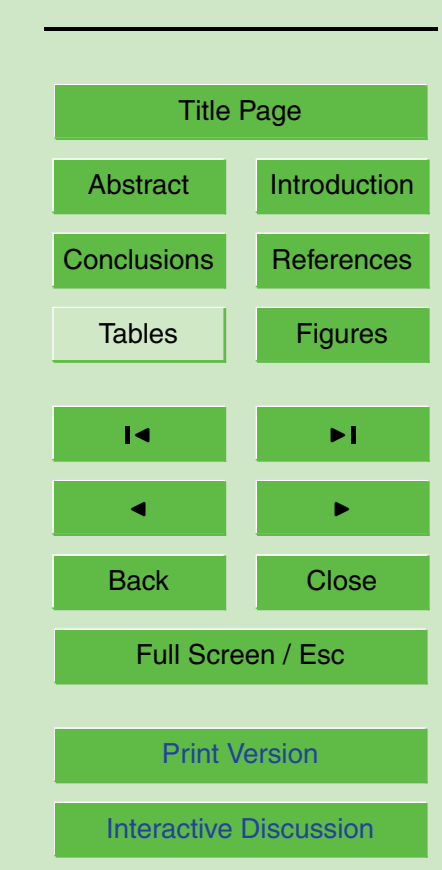

EGU 
ties and the solar activity shows a magnitude of 1 to 4 years for different cycles of solar activity (Dorman et al., 1987a). It is worth mentioning the fact that both phenomena are in opposite phases (Dorman et al., 1987b; Novikov et al., 1984; Reap 1986; Jaani, 1973). The determination of the hydrologic "dephasage" relative to solar activity, and 5 the determination of the laws of variation of such shifts leads to the development of quantitative long period prognostic of the water volumes of big lakes.

\section{The basic formulation for the spectral analysis}

For the determination of the dephasages, the precision of their magnitudes and the study of the general cyclicities in the data of water volumes of lakes and solar activity, we have employed the traditional methods of spectral analysis, assuming a quasistationary status of the processes under consideration.

The spectral methods have been widely described by Jenkins and Watts (1971) and Key and Marpl (1981); here, we will limit ourselves to a brief description of the basic formulae of our concern. To search for general cycles in the data series we use the 15 Blackman-Tiuki method, based on the Fourier transform of the correlation function of the original process $\{x(n)\}$.

$P(f)=\Delta t \sum_{m=-M}^{M} R_{X X}(m) \exp (2 j f m \Delta t) \omega(m)$,

where

$R_{x x}=\frac{1}{N-m} \sum_{n=0}^{N-1} x(n+m) x(n)$

20 is the centered estimation of the correlation function; $\omega(m)$ is a weight function (the correlation window); $\Delta t$ is the discretional interval of data. In practice, to improve the

\section{Influence of solar activity on hydrological processes}

J. Pérez-Peraza et al.

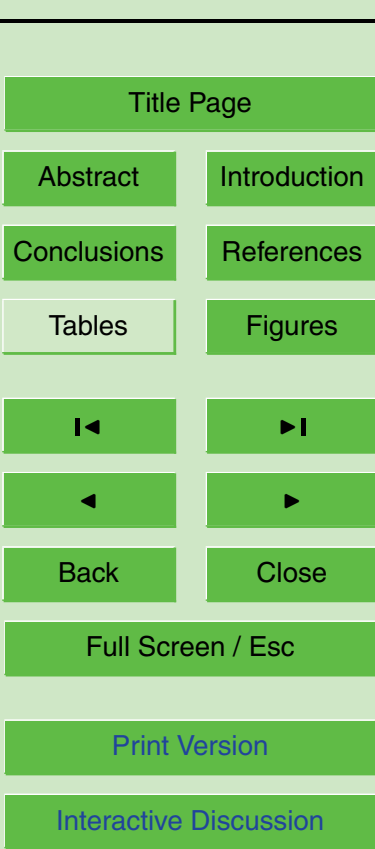


statistical properties and the significance of the results one uses the non-centered estimation of the correlation function

$R_{x x}=\frac{1}{N} \sum_{n=0}^{N-1} x(n+m) x(n)$.

$2,605-637,2005$

In fact, it is not difficult to show that the application of the non-centered estimation is 5 equivalent to the introduction of a complementary weight function $\omega(m)$, which gives the possibility of obtaining a lower mean quadratic error in the estimation of the spectrum.

The choice of a certain window, as well as its width (Jenkins and Watts, 1971; Key and Marpl, 1981), is made according to the requirement of a reduction of the lateral ripples that appear as a result of the spectrum convolution of the weight function and the spectral peak; also, the dimension and form of $\omega(m)$ determine the resolution of the estimation.

In this work we use the following high frequency filters:

1. the filter of First Differences:

$$
y_{t}=x_{t+1}-x_{t}
$$

2. the filter of Butterworth:

$$
y_{t}=2 a y_{t-1}+b y_{t-2}+x_{t}-2 x_{t-1}+x_{t-2}
$$

where

$$
\begin{aligned}
& a=\frac{\omega_{c}^{2}-1}{1+\sqrt{2} \omega_{c}+\omega_{c}^{2}}, \\
& b=\frac{1-\sqrt{2} \omega_{c}+\omega_{c}^{2}}{1+\sqrt{2} \omega_{c}+\omega_{c}^{2}},
\end{aligned}
$$

\section{Influence of solar activity on hydrological processes}

J. Pérez-Peraza et al.

Title Page

Abstract

Conclusions

Tables

14

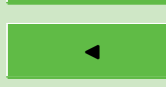

Back

Full Screen / Esc 
and $\omega$ is the cutoff frequency (Selesnick and Burns, 1998).

For the low frequency filters we use:

$2,605-637,2005$

1. the filter of Gauss:

$$
y=\frac{1}{N} \sum_{i=1}^{N} \alpha_{i} x_{t+1}
$$

Influence of solar activity on hydrological processes

where $\alpha_{i}$ are the Gauss coefficients,

2. the filter of Butterworth:

J. Pérez-Peraza et al.

$$
y=2 a y_{t-1}+b y_{t-2}+x_{t}+2 x_{t-1}+x_{t-2} .
$$

To obtain the cross estimations (i.e. for the determination of common cycles to all the processes) we employed the methods of cross spectral analysis, which allows the estimation of the cross spectral amplitude $(A)$, the phase spectrum $(F)$ characterizing the shift between the analyzed processes at different frequencies and the coherence spectrum $(K)$ determining the correlation degree of the series at different frequencies.

The reliability of the results was controlled by means of the simultaneous application of different spectral analysis methods and special procedures: data filtering, widening of the spectral windows, and others, as well as the calculation of the maximum value of the cross correlation coefficient with respect to the shift used to obtain the estimations of dephasage between the processes $\left\{x_{n}\right\}$ and $\left\{y_{n}\right\}$ :

$K(\tau)=\frac{1}{N} \sum_{n=1}^{N-\tau}\left(x_{n}-\hat{x}\right) \frac{\left(y_{n+\tau}-\hat{y}\right)}{\sigma_{x}^{2} \sigma_{y}^{2}}$.

Furthermore, the reliability of the estimations was controlled by applying the spectral

analysis methods to the test data, in particular to the velocity of the wind in the Baltic Sea and to the $K_{p}$ index, corresponding to the same periods of analysis of the water volumes of Lake Tchudskoye (Dorman et al., 1987a, b).

Title Page

Abstract Introduction

Conclusions References

Tables Figures

14

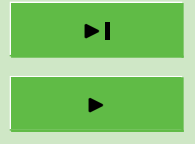

Back

Close

Full Screen / Esc

Print Version

Interactive Discussion 


\section{Procedure and results of the spectral analysis}

The analysis of the spectral characteristics was made with the series of the annual mean values of solar activity, water volume of Lake Tchudskoye from 1885-1987; the $K_{p}$ index from 1920-1984, atmospheric characteristics from 1934-1985 and the cosmic

5 ray intensity from 1947-1987 (ionization chambers). The length of the studied series (with the possible exception of that of cosmic rays) allows with reliance to determine the quasibiannual (Gulinsky et al., 1988) up to the secular (Jaani, 1973) cycles; the application of the spectral methods permits the estimation of not only the shift between the different processes but also among each one of the cyclic components of each 10 particular process (with relation to $S$ ). From the mentioned statements a number of conclusions can be drawn that agree with the results obtained previously by Jaani (1973):

1. the cross correlation functions of the initial series present well defined cycles: one of 11 years (Fig. 1a) and another of secular nature (Figs. 1b and 1c); a way to test

The calculations of the cross correlation functions of $H$ and $P$ show a good agreement with the results of Gulinsky et al., (1988): the notorious dephasage between $H$ between 80 and 90 years (Fig. 1d);

2. the correlation function of the water volume series $H$ shows a clear cycle of 22 years, and has its reflection in the cross correlation functions of the filtered data by the Gauss technique: moving average of 7 years with coefficient of Gauss (see Fig. 1c).

3. the presence of a 11 year cycle can be seen clearly in the correlation functions of Fig. 1b, after the application of the First Differences filtration technique (smoothing the tendency); the maximum of the cross correlation function was obtained by shifting the series $\mathrm{H}$ relative to the series $S$ in 2 and 3 years.

\section{HESSD}

$2,605-637,2005$

Influence of solar activity on hydrological processes

J. Pérez-Peraza et al.

\section{Title Page}

\section{Abstract}

Introduction

Conclusions

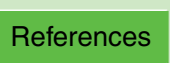

\section{Tables}

14

$\triangleleft$

Back
Figures

$\rightarrow$ I

\section{Full Screen / Esc}

Print Version

Interactive Discussion 
and $P$ agrees with similar results for the series of $P$ and Wolf numbers $W$ (Dorman et al., 1987a). The calculations of the cross correlation functions between solar activity $(S)$ and geomagnetic activity $\left(K_{p}\right)$ shows a dephasage of about $1-2$ years among them, in the course of time. Besides, the cross correlation analysis between $H$ and

$5 K_{p}$ reveals a delay of the water volume in 1-2 years (the processes result in opposite phases), which agrees with the delay of $H$ relative to $S$.

The calculation of the power spectrum of each one of the analyzed processes shows the presence of a complex structure, in particular in the zones of high frequency (periods of 2-6 years), as well as the existence of variations of 2-3 years, 11 years, 22 years 10 and secular variations in both the water volume and solar activity data (Fig. 2). The obtained results coincide quite well with the results of other analyses of different geophysical and heliophysical processes carried out previuosly (King, 1974; Mayaud, 1977; Ribin, 1985; Dragan et al., 1984; Olh et al., 1985; Bazilievskaya et al., 1984): the spectral analysis of the solar activity, the geomagnetic field, heliospheric pulsations and atmospheric pulsations reveal similar periods. The analysis of the cross spectra (Fig. 3) show that in the time series of the water volume of Lake Tchudskoye, four cycles can be distinguished that can be confidently related to solar activity and atmospheric processes:

1. The quasibiannual period, which is possibly related with the quasibiannual variations of the solar wind, as well as with the corresponding temporal variations of atmospheric pressure and temperature (Djzhaniashville et al., 1985; Labitzk and VanLoon, 1988). It should be emphasized that though such interpretation of the quasibiannual variations of the water volume of Lake Tchudskoye is preliminary the correlational link $\left(r \sim 0.7, K^{2} \simeq 0.6\right)$ make such an explanation highly probable.

2. The 11 year cycle, related with solar activity (either with the surface of sunspots, $S$, or with the Wolf number, $W$ ) is also present in the water volume through analogous oscillations of the earth climate (Gulinsky et al., 1988; Olh, 1985; Plakhotniuk, 1980; Vitinskiy et al., 1986; Friis-Christensen and Lassen, 1992). In fact,

\section{Influence of solar activity on hydrological processes}

J. Pérez-Peraza et al. 
the comparison of the power spectra of the water volumes of Lake Tchudskoye with analogous spectra of atmospheric parameters (Dragan et al., 1984) shows, not only a good coincidence of relevant peaks, but also a high degree of correlation among them: $r \sim 0.7$ between $H$ and $P\left(K^{2} \sim 0.6\right) ; r \sim 0.9$ between $H$ and $S$; $K(\tau) \sim 0.9\left(K^{2} \sim 0.8\right)$.

3. The 22 year cycle, prevailing in the water volume variations and standing out in the power spectra (Figs. 2a, 3a and 3c) and in the correlation functions (Fig. 1d). This cycle coincides with analogous cycles in climatic data. Rojzkov (1988) presents the spectral analysis of a 1000 year series, corresponding to a index which describes the rate of the Deuterium content relative to Hydrogen in the annual rings of trees (the variation of this index is proportional to the variation of the atmospheric temperature). As a result, a period of $22.36 \pm 0.04$ years was obtained, very close to the 22 year cycle of the solar activity related with the evolution of the general solar magnetic field. The closeness of both cycles in the water volumes, in the atmospheric characteristics and in the solar activity is an argument supporting their intercorrelation. It has been shown by Olh (1975) that the 11 year solar activity cycle, characterizing the evolution of sunspots has a weaker influence on meteorological and climatological processes than the 22 year cycle of inversion of solar magnetic field. Both the 11 and 22 year cycles show a high reliability: $r \sim 0.7$ between $H$ and $S ; r \sim 0.75$ between $H$ and $P(K(\tau) \sim 0.5)$. It must be emphasized that the presence of the 22 year cycle of the solar activity on the earth climate has, as a general rule, a regional nature (Olh, 1983); that is, the climate variations related with the cycle of 22 years have different amplitudes and opposite phases in different regions of the planet. It is interesting to note that the cross phase spectra between $H$ and $S$ for one side, and $P$ and $S$ by other side, give close results with little time variation, which seems to reveal the existence of a general mechanisms for the appearance of the 22 year variations in the water volumes and in the atmospheric parameters.

HESSD

2, 605-637, 2005

\section{Influence of solar activity on hydrological processes}

J. Pérez-Peraza et al.

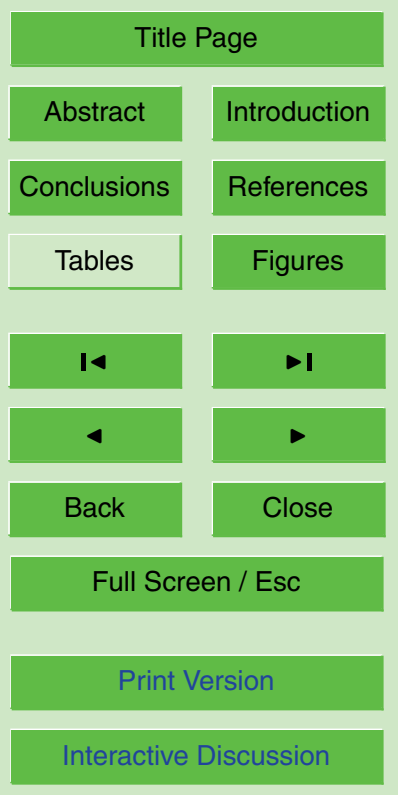

EGU 
4. The secular cycle (80-90 years), which is observed in the power spectra in the form of a small amplitude peak $(2 \sigma \leq A \leq 3 \sigma)$ in the zone of low frequencies (Figs. $3 \mathrm{a}$ and $3 \mathrm{c}$ ) is discernible due to the attenuation of the correlation function of the water volumes $H$ (Fig. 1d). The calculation of the correlation coefficients for the secular variation of the water volumes confirm the statistical significance of the observed peak $(K(\tau) \sim 0.6 ; K(\tau) \sim 0.4)$, although its determination by traditional methods has certain methodological difficulties.

\section{Autorregressive analysis to improve the reliability of the results}

It must be remarked that the calculations associated with the oscillations of Lake 10 Tchudskoye (Libin and Jaani, 1989) need very extensive computer time. For this reason, in the process of comparing the spectral and temporal characteristics of the oscillations of both lakes, when the results of the spectral analysis (Blackman-Tiuki type) coincide the calculation was not repeated for the level oscillations of Lake Pátzcuaro. Besides, it must be kept in mind that the cross power spectra give confident estimations

15 of the intercorrelations among the observed processes, which allows the estimation of the shift among them. However, the reliability of a series of relations is just in the limit of reliability of the obtained results, so that, to certain extent, it is the skill of the investigator that plays the main role in the selection of the analysis methods, and the estimation of the truthfulness of the results. For this reason, in subsequent analysis we 20 used the autorregressive spectral analysis (ARSA), described recently by Yudakhin et al. (1991) and Libin and Jaani (1989). The main difference between the ARSA and the standard methods is the possibility to apply the ARSA to quasi-stationary processes (as the series analyzed here), and the possibility to estimate intercorrelations between the analyzed series, with a reliability of $100 \%$ in the frequency space. However, it must be reminded that the amplitudinal estimations obtained with the ARSA are relatives (i.e. though their temporal behavior is absolutely comparable, it cannot be related to the initial series). In other words, even if it is not possible to relate the calculations of

HESSD

2, 605-637, 2005

Influence of solar activity on hydrological processes

J. Pérez-Peraza et al.

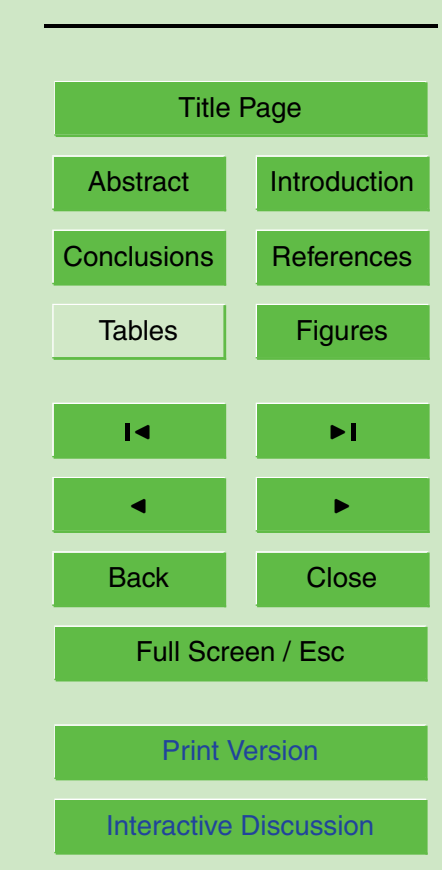

EGU 
the amplitudinal spectra to the original data in an absolutely exact form, their temporal dynamics may be reproduced univocally.

The analysis of the oscillations of the levels of Lake Pátzcuaro (in Mexico) and Lake Tchudskoe (in Russia), as well as the oscillations of solar activity, were carried out 5 on the basis of monthly and annual series: in particular, from December 1921 to January 1993 for Lake Tchudskoye, and from January 1950 to January 1993 for Lake Pátzcuaro. The methodology for the calculation of spectra by means of autorregressive (AR) models leads to obtain the correlation functions, the cross correlation functions, the symmetric part of the correlation functions, and both the symmetric and asymmetric 10 parts of the cross correlation functions, from which one can proceed to the determination of the order of the AR model for the analyzed series. Using the results obtained in this way, the residual dispersion of both series is determined, and finally, the definitive orders of the AR and MA (number of equations) of the models for each series is obtained.

15 The result of the calculation of the spectral characteristics of Lake Tchudskoye by means of AR-MA models of order 5-7, for the period 1921-1932 is shown in Figs. 5a$5 \mathrm{e}$ (the coherence of the processes was not calculated). In the following figures we present: the amplitude spectrum of solar activity (Fig. 5a); the oscillations of Lake Tchudskoye (Fig. 5b), the cross amplitude spectra (Fig. 5c) and the crossed phase spectrum (Fig. $5 \mathrm{~d}$ ). It is important to remark that the results clearly reveal oscillations of Lake Tchudskoye with periods of 1.5-2.0 and 9.06 years, all of them related with solar activity. Analogous measurements for the period 1932-1943 (Figs. 6a-6d), 1943-1953 (Figs. 7a-7c), and 1953-1985 (Figs. 7e-7f), show similar results, that is, periodicities of 2-4 and 8-9 years which are also related to solar activity.

25 To be convinced of the precision and reliability of the estimations, it was decided to carry out the complete autorregressive analysis of the oscillations of the studied lakes, and the solar activity, in the following order:

1st. AR-MA analysis of the oscillations of both lakes for the period 1950-1987;

2nd. AR-MA analysis of the oscillations of Lake Tchudskoye and solar activity for the

HESSD

2, 605-637, 2005

\section{Influence of solar activity on hydrological processes}

J. Pérez-Peraza et al.

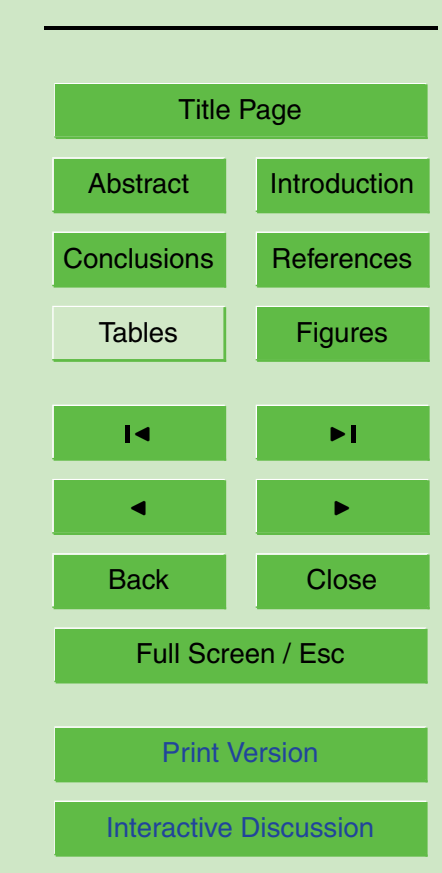

EGU 
same period, and

3rd. AR-MA analysis of the oscillations of Lake Pátzcuaro and solar activity for the same period.

Figures $8 \mathrm{a}$ and $8 \mathrm{~b}$ show the behavior of the level of lakes in the period 1950-1987.

5 At least two remarkable features stand out from both figures: the evidence of a variation of 22 years, and that the oscillations of the level of both lakes are in opposite phases. The calculation of the cross correlation functions between the two lakes support those conclusions: Fig. 9 shows a clear anticorrelation $(\simeq 0.6)$, with a delay of 1 to 2 years in the annual series.

10 The autorregressive analysis of the variations of Lakes Pátzcuaro and Tchudskoye in the annual means (Figs. 10a-e) reveals the presence of oscillations with periods of about 4, 11 and 22 years in the course of all the analyzed period. A high resolution of spectra in the region of low frequencies led to separate waves of 11 and 22 years, resulting with amplitudes completely comparable. On this basis, the periodic15 ity of 22 years was artificially eliminated in subsequent calculations. Figure $10 \mathrm{~d}$ shows the dephasage between the oscillations of both lakes. An important result is illustrated in Fig. 10e, which shows that the coherence of both processes is particularly high, of the order of 0.8 for the oscillations of 22 years, about 0.6 for the 4 years and about 0.3 for the 11 years oscillation. The comparison of the amplitudes shows a relative elevation, 2-3 times, in the oscillations of Lake Tchudskoye with respect to the Lake Pátzcuaro.

The AR-MA analysis of the levels of the lakes and solar activity leads to a number of important conclusions, for further calculations. Figure 11 presents the results of the AR-MA spectra of amplitudes of solar activity in the period 1950-1985. The comparison of these spectra with those of the lakes (Figs. 10a and 10b) reveals an absolute coincidence in the presence of the oscillations, mainly for those with periods of 4 years. The cross amplitudinal spectra of the levels of both lakes and the solar activity (Figs. 12a and 12b), the coherence spectra (Figs. 12c and d), as well as the phase spectra (Figs. 12e and 12f) confirm the above mentioned conclusions about the

\section{Influence of solar activity on hydrological processes}

J. Pérez-Peraza et al.

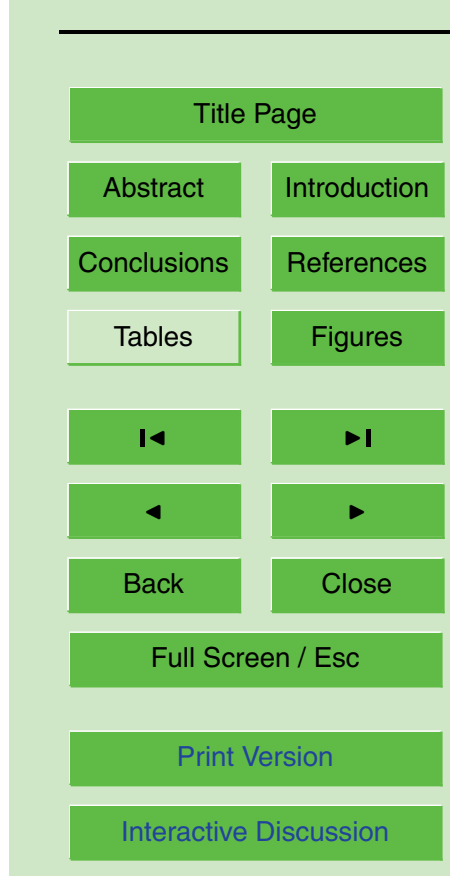


behavior of both lakes, and in addition, confirm in an univocal form, the solar origin of the 9-11 years oscillations (in agreement with the solar activity cycle) and the 4 years oscillation, all this with a coherence coefficient of about 1.

\section{Conclusions}

5 The results show good coincidence with the results of similar calculations for essentially distinct correlational windows (e.g. those of Barttlet, of Jinchin and of Berg) by using recursive filters of Butterworth, which have spectral properties that are also significantly distinct. The employment of recursive filters gives good results for the estimation of power spectra by means of autorregressive models. However, that is beyond the scope of the present work and should be studied by an independent analysis.

Hence, the correlational and spectral analysis of the data of the level of Lake Tchudskoye have confirmed thefollowing facts: the proposed relation between water volumes and solar activity (Jaani, 1973; Reap, 1981), the existence of water volume variations of Lake Tchudskoye of statistical significance with periods of 2.6, 11.2, 22 and 8090 years and the dephasage of $\mathrm{H}$ relative to $S$ oscillates from 1 up to $3 \sim 4$ years, depending on the solar activity cycle. For the odd cycles, the maximum of the water volume is delayed two years relative to the minimum of solar activity. For the even cycles, the delay is around 3 years (Fig. 4). It must be remarked that the structure of water volume histograms for even and odd cycles is different, which also supports the thesis of a prevailing 22 years periodicity in the atmospheric and hydrologic processes.

The employment of all the spectral mathematical formalisms existing up to date, and the confrontation of results of different calculations (for instance, Fig. 3 and Figs. 912) show that the source of the oscillation mechanism of the level of closed lakes (of the type of the Lake Pátzcuaro in México, Lake Tchudskoye in Russia and Estonia, the Carpio sea in Russia, or the Great Lakes in United States of America) is the solar activity cycle, through its influence on the earth magnetosphere and atmosphere. The obtained results lead (in an autoconsistent manner) to the development of an autorre-

Influence of solar activity on hydrological processes

J. Pérez-Peraza et al.

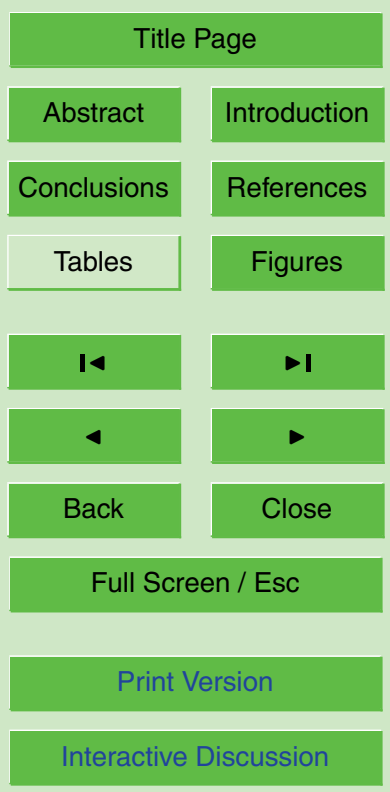

EGU 
gressive model to forecast the oscillations of lakes (Dorman, 1987a, b) by means of formulations of the following type:

$Z_{t}=\sum_{i=1}^{t-k} \alpha_{t-i} Z_{t-i}+\sum_{i=1}^{t-l} \beta_{t-i} Y_{t-i}+\sum_{i=1}^{t-m} \gamma_{t-i} X_{t-i}+\xi_{t}$

where:

$Z_{t} \quad:$ the oscillation of the forecasted lake,

$Z_{t-i} \quad:$ the oscillation in previous years of the level of the studied lake, with a total shift of $k$ years,

$Y_{t-i} \quad$ : variation of solar activity in previous years with a total shift of / years (under the restriction $/ \geq k$ ),

$X_{t-i} \quad$ : variation of the level of any other lake in previous years (for Lake Tchudskoye),

$\xi_{t-i} \quad$ : residual function related with the temperature, or precipitations in the neighbor zones to the lake, during the previous years and

${ }_{5} \alpha, \beta, \gamma:$ regression coefficients.

Finally it is worth mentioning the possibility that in the future, some ecological disasters (as those of the Caspio sea in the years 80's, and Lake Tchudskoe in 1924) 10 may be avoided on basis to scientific prognosis. However, it is necessary to take into account that no scientific prognostic can substitute the good common sense of people and governments; otherwise, in spite of excellent forecasting models, new ecological catastrophes may occur as that of the Aral Sea in Turkmenia and Uzbekistan.

\section{References}

15 Ariel, N. Z., Schakhmeister, V. L., and Murashova, A. V.: Spectral Analysis of characteristics of energetic exchange between ocean and atmosphere, Meteorologic i Gidrologia, 2, 49-53, 1986.

\section{Influence of solar activity on hydrological processes}

J. Pérez-Peraza et al.

\section{Title Page}

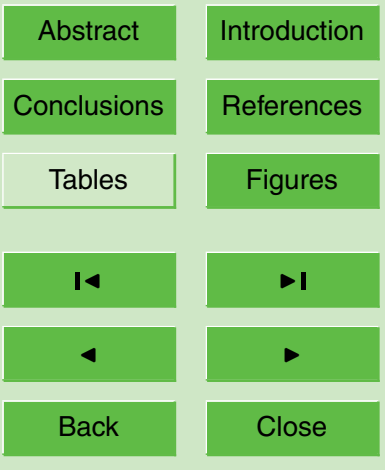

Full Screen / Esc

Print Version

Interactive Discussion 
Baliunas, S. and Soon, W.: Are variations in the length of the activity cycle related to changes in brightness in solar-type stars?, Astrophysical Journal, 450-2, 896-901, 1995.

Bazilievskaya, T. V., Vernova, Ye. S., and Grigoryan, M. S. et al.: On the change of the period of variation of cosmic rays associated to the rotation of the Sun, Geomagn. \& Aeron., 24-4, 5 552-556, 1984.

Chertkov, A. D.: Solar Wind, The Internal Structur of the Sun, Moscow, 1985.

Chijzhevskiy, L. A.: Terrestrial Echo of the Solar Storms, Moscow, 1976.

Djzhaniazhvili, T. V., Rogova, O. G., Zhatazhvili, L. Kh., and Shafer, Yu. V.: Almost two-year variation of galactic cosmic rays, geomagnetic activity, atmospheric temperature and pressure,

10 Trudi Instituta Geofiziki AN GruzSSR, 53, 94-100, 1985.

Dorman, L. I., Libin, I. Ya., Mikalayunas, M. M., and Yudakhin, K. F.: Relationship between geophysical and cosmophysical parameters in the 19th and 20th cycles of solar activity,Geomagn. \& Aeron., 27-2, 303-305, 1987a.

Dorman, L. I., Libin, I. Ya., Mikalayunas, M. M., and Yudakhin, K. F.: Variations of geophysical and cosmophysical parameters in the 18 th trough 21th cycles of solar activity, Geomagn. \& Aeron. 27-3, 483-485, 1987b.

Dragan, Ya. P., Rojzhkov, V. A., and Yavorskiy, N. N.: Applying methods of the periodical and correlated stochastic processes into the probabilistic analysis of oceanological time series, in Probabilistic Analysis of Oceonological Time Series, Leningrad, 4-23, 1984.

20 Eipre, T.: Peipsi-Pikhva järve veeseisud, Eesti Geograafia Seltsi Aastaraamat 1963, Tin., 3554, 1964 (in Estonian).

Eipre, T.: Eesti mageveeolud ja veeolude reguleerimine, I. Eesti Loodus 9, 549-556, 1971 (in Estonian).

Feynman, J.: Geomagnetic and solar wind cycles, 1900-1975, J.G.R. A87-8, 6153-6162, 1982.

Friis-Christensen, E. and Lassen, K.: Global temperature variations and a possible association with solar activity variations, Scientific Report 92-3, Danish Meteorological Institute, Copenhagen, 1992, also, Sky \& Telescope, 489, 1992.

Friis-Christensen, E. and Lassen, K.: Solar Cycle and Atmospheric Warning, Sky and Telescope, 90-5, 12-13, 1995.

30 Friis-Christensen, E. and Lassen, K.: Length of the solar cycle as indicator of solar activity closely associated with climate, Science, , 254, 698-700, 1991.

Gulinsky, O. V., Guschina, R. T., Dorman, L. I., Libin, I. Ya., Mikalayunas, M. M., and Yudakhin, K. F.: Modelling the mechanism of heliophysical parameters influence on the atmospheric

HESSD

2, 605-637, 2005

Influence of solar activity on hydrological processes

J. Pérez-Peraza et al.

\section{Title Page}

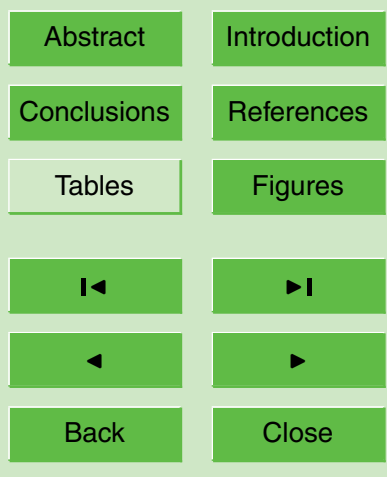

Full Screen / Esc

Print Version

Interactive Discussion 
processes, Kosmicheskiye luchi, 26, 5-51, 1988.

Halenka, J.: The connection between characteristic values of the 11-year cycles of solar and geomagnetic activity, Stud. Geophys. Geod. 30-2, 153-157, 1986.

Jaani, A.: Veerohkus muutub tsükliliselt, Eesti Loodus 12, 758-764, 1973 (in Estonian).

5 Jaani, A.: How to call Tchudskoe Lake? Izvestia AN ESSR. Biol., 36-2, 169-172, 1987.

Jenkins, G. and Watts, D.: Spectral Analysis and its Applications, Vip. 2, 288 p., MIR Moscow, 1971.

Kenig, Ye. L. and Djzhivilov, I. A.: On the proyect of a continuos Pskov-Yurev-Narva Aquatic Way, Saint Petersburg, 1909.

10 Key, S. M. and Marpl, S. L.: Modern methods of spectral analysis, Communications of the Institute of Electronics and Radioelectronics 69-11, 5-48, 1981.

King, J. W.: Wheather and the earth magnetic field, Nature, 247, 131-134, 1974.

Labitzke, K. and VanLoon, H.: Associations between the 11-year cycle, the QBO and the atmosphere, J. Atmos. Terr. Phys., 50, 197-200, 1988.

Libin, I. Ya., Gushchina, R. T., Pérez-Peraza, J., Leyva, A., and Jaani, A.: Influence of solar activity variations on hydrological processes (autorregressive analysis of solar activity and levels of lakes, Geomagnetism \& Aeronomy, 36-1, 79-83, 1996.

Libin, I. Ya., Gulinsky, O. B., Guschina, R. T. et al., Modeling the mechanism of heliophysical parameters influence on atmospheric processes, Kosmicheskie Luchi 26, 22-56, 1992.

20

Libin, I. Ya. and Jaani, A.: Influence of variations of solar activity on geophysical and hydrological processes, Izvestia AN Estonii 38-2, 97-100, 1989.

Mayaud, P. N.: On the realibility of the Wolf number series for estimating long-term periodicities, J Geophys. Res., 82-7 1271-1272, 1977.

Novikov, A. M., Starina, V. A., and Skriabin, N. G.: Recording spectra of the time variations of cosmic ray intensity and atmospheric pressure, Bulletin NTI Yakutsk 4, 3-6, 1984.

Olh, A. I.: Rithmic processes in terrestrial atmosphere, Leningrad, 1973.

Olh, A. I.: 22-years cycle in air temperature of north hemisphere and in tree rings, Solnechnie Dannie, 12, 69-72, 1985.

Pérez-Peraza J.: Space Plasma Physics, in: Annals of the Space conference of the Americas: perspectives of cooperation for the development, edited by the PNUD, 1, 96-113, 1990.

Pérez-Peraza, J., Leyva, A., Libin, I. Ya., Formichev, V., Gujschina, R. T., Yudakhin, K., and Jaani, A.: Simulating the mechanism of the action of heliophysical parameters on atmospheric processes, Geofsica Internacional, 36-4, 245-280, 1997.
HESSD

2, 605-637, 2005

Influence of solar

activity on

hydrological

processes

J. Pérez-Peraza et al.

\section{Title Page}

\section{Abstract}

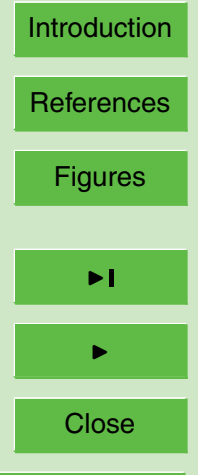

Back

Close

Full Screen / Esc

Print Version

Interactive Discussion 
Plakhotnyuk, V. N.: Peculiarities of the cycles of solar activity and geoeffectivity of interplanetary medium, Kosmicheskie Luchi 21, 75-84, 1980.

Reap, A.: Peipsi-Phikhva järve veeseisude prognoosist, Maaparandus Teaduslik-technilisi uurimistulemusi, 17-24, 1981, (in Estonian).

5 Reap, A. O.: On the possibility of ultralong term forecasting water content of the TchudskoePskovskoe Lake, Proceedings of the XI Republican Hydrometeorological Conference on Problems and ways in the rational usage of natural resources and protecting of the nature, Shiauliay, 80, 1986.

Ribin, Yu. R.: Spectral analysis of amplitude variations of the 11-year cycle of solar activity, Solnechnie Dannie 9, 78-82, 1985.

Rojzhkov, V. A.: Methods of probability analysis of oceonological processes, Leningrad, 1988.

Selesnick, I. W. and Burns, C. S.: Generalized digital Butterworth filter design, IEEE Trans. on Signal Processing, 46, 6, 1688-1694, 1998.

Shpindler, I. B. and Zengbush, A.: Lake Tchudskoye, Izvestia Imperial Russian Geographycal 15 Society, 32-4, 1896.

Smirnov, N. P.: Space-time regularities of long-term oscillations of the lake consumption in USSR, Proceedings of the IV All-Union Hydrological Congress, 3, 1975.

Vitinskiy, Yu. I., Konetzkiy, M., and Kuklin, G. V.: Statistics of the sun spot Formation Activity, Leningrad, 1986.

20 Xanthakis, J., Mavromichalakai, H., Petropulos, and B.: Cosmis ray intensity related to solar and terrestrial activity indices in solar cycle No. 20, Astrophys. Space Sci., 74-2, 303-317, 1981.

Velner, A.: Peipsi perioodi, Tee ja Tehnika, no. 2, 22-24, 1929 (in Estonian).

Velner, A.: Veepinnad Narva jme ja Peipsi järve vesikonnas 1929-1938, Loodisvarade Instituudi Avaldised, no. 6, 1940 (in Estonian).

Yudakhin, K. F., Libin, I. Ya., and Prilutzkiy, K.: autorregressive analysis, Preprint IZMIRAN No. 16, 1991.

Zatopek, A., Krivaky, L.: and Lastoviska, J.: Correlation between solar, interplanetary, geomagnetic, ionospheric, and atmospheric circulation, J. Inter. Cycle Res. 7-1, 9-13, 1976.

30 Zilhs, V., Mitrikas, V. G., Petrov, V. M., Okhlopkova, L. S., Oklopkov, V. P., and Charakhchian, T. N.: Quasi-periodical variations in the manifestations of solar activity, Kosmicheskie issledovaniya 25-2, 325-328, 1987.

HESSD

2, 605-637, 2005

Influence of solar activity on hydrological processes

J. Pérez-Peraza et al.

Title Page

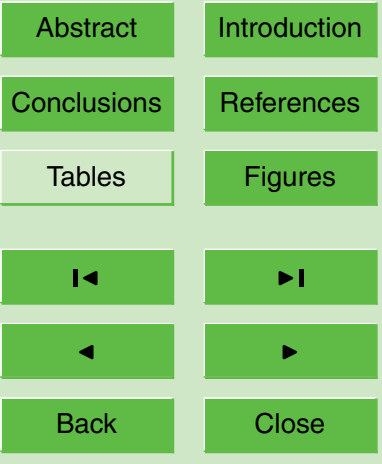

Full Screen / Esc

Print Version

Interactive Discussion 


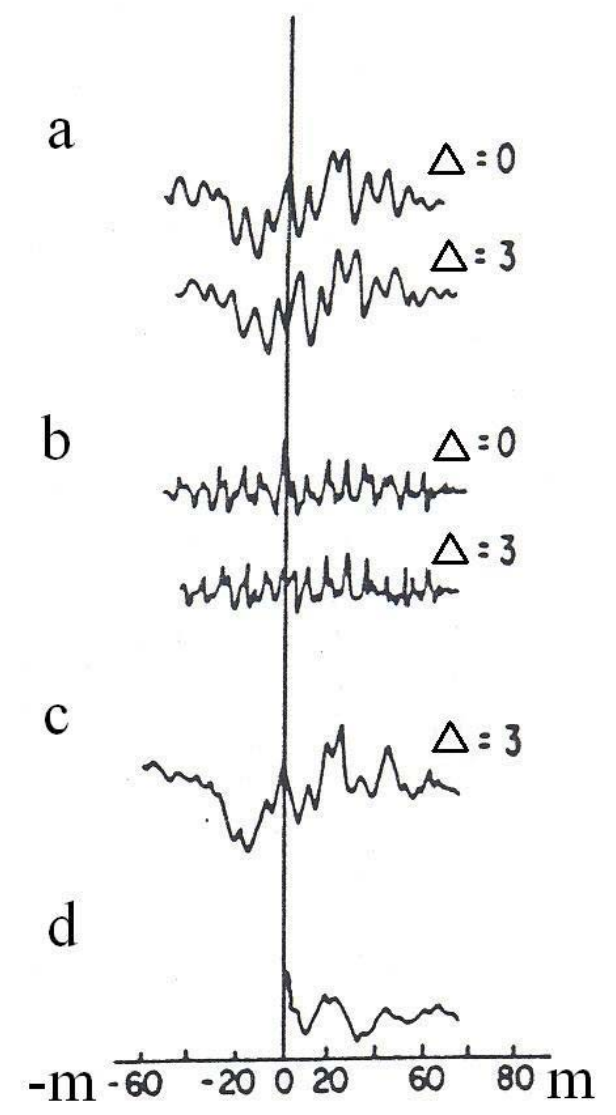

Fig. 1. The cross correlation functions between solar activity and water level of Tchudskoye lake without shift $(\Delta=0)$ and with shift $(\Delta=3)$ between the sets of data series: (a) for the original series; (b) for the series filtered by the First Differences filter; (c) the same filtered by the Gauss filter; (d) correlation function of Lake Tchudskoye.

\section{HESSD}

2, 605-637, 2005

Influence of solar activity on hydrological processes

J. Pérez-Peraza et al.

Title Page

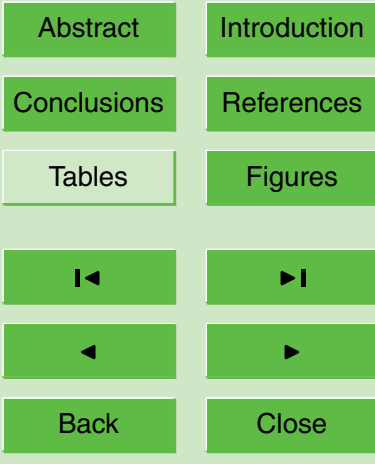

Full Screen / Esc

Print Version

Interactive Discussion 


\section{HESSD}

2, 605-637, 2005

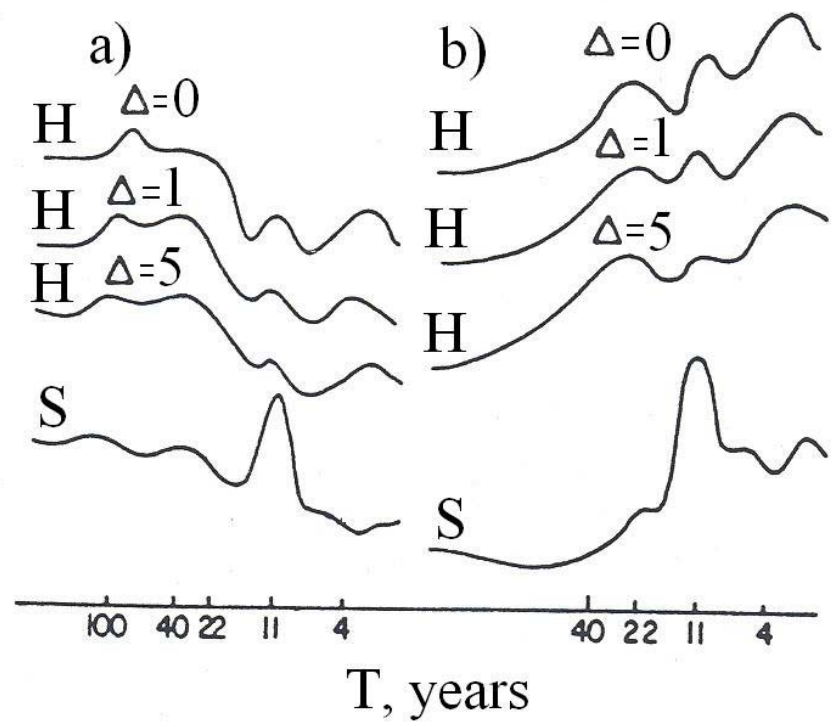

Fig. 2. Power spectra for solar activity $S$ and water level of Lake Tchudskoye $H$ without shift $(\Delta=0)$ and with shifts $(\Delta=1, \Delta=5)$ between the sets of data series: (a) for the original series; (b) for the series filtered by means of the First Differences filter.

\section{Influence of solar activity on hydrological processes}

J. Pérez-Peraza et al.

\section{Title Page}

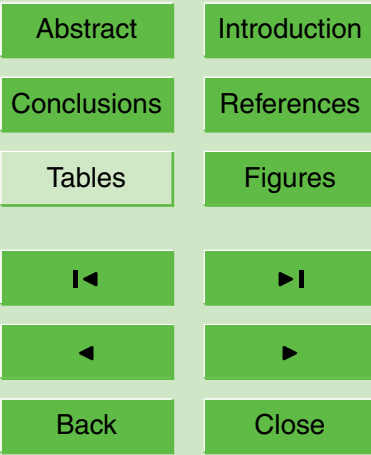

Full Screen / Esc

Print Version

Interactive Discussion 


\section{HESSD}

2, 605-637, 2005

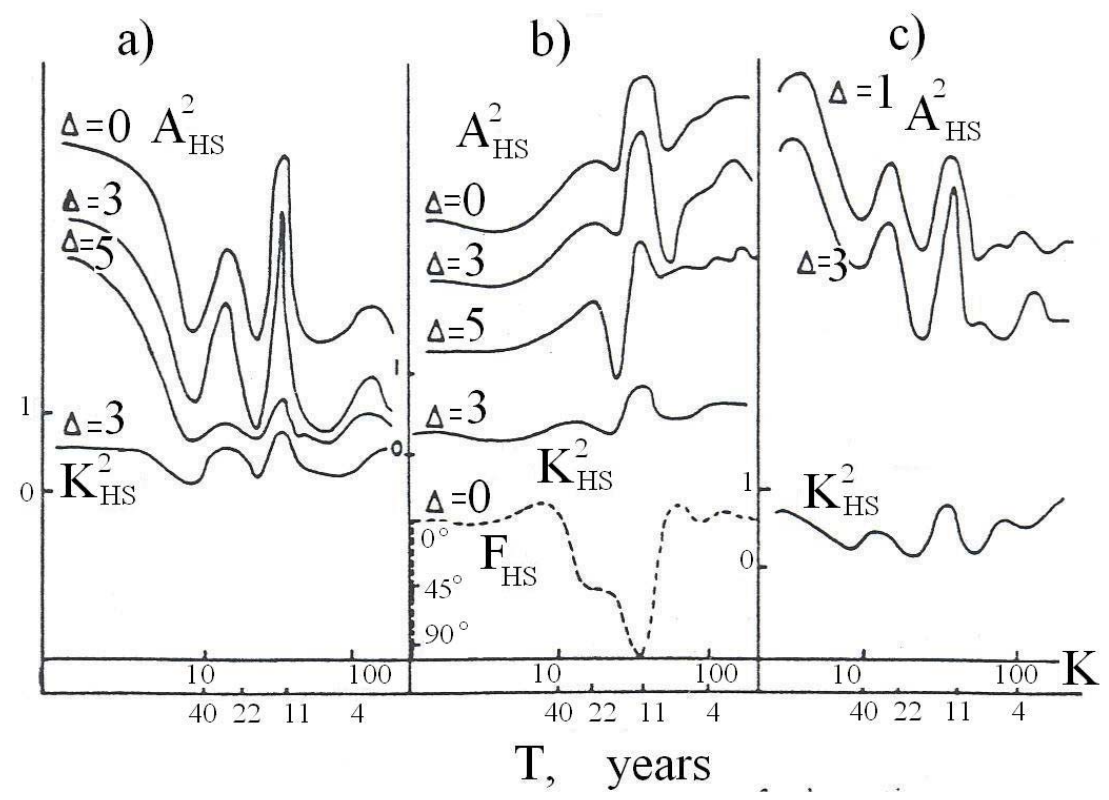

\section{Influence of solar activity on hydrological processes}

J. Pérez-Peraza et al.

\section{Title Page}

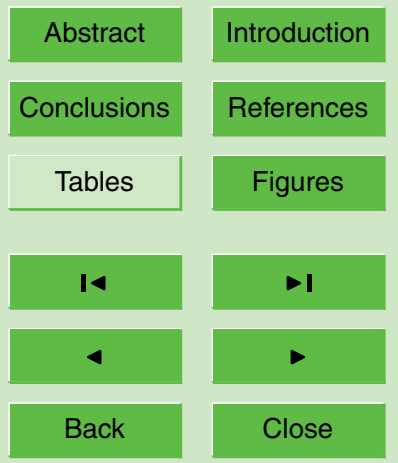
Fig. 3. Cross amplitud spectra of solar activity and water level of Lake Tchudskoye $(A)$,
phase spectra $(F)$ and coherence spectra $(K)$, without shift between series $(\Delta=0)$ and with it $(\Delta=1,3,5)$. (a) for the original series; (b) for series filtered by means of the First Differences

Full Screen / Esc filter; (c) for series filtered by means of the Gauss filter.

Print Version

Interactive Discussion 


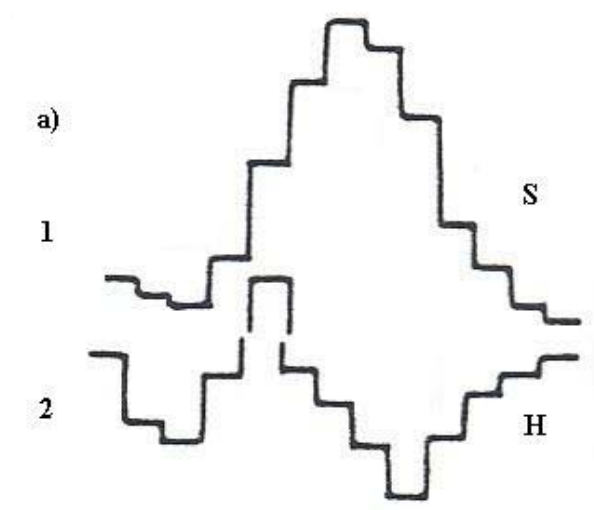

HESSD

$2,605-637,2005$

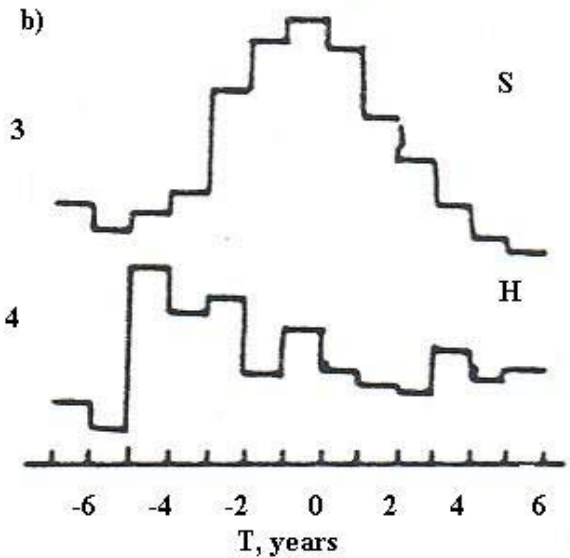

Title Page

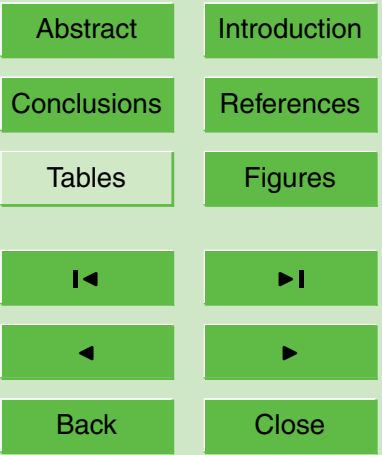

Fig. 4. Behavior of solar activity $S$ and the water level of Lake Tchudskoye $H$ averaged by

Full Screen / Esc means of the overlaping periods: (a) 1 and 2: the odd cycles of solar activity; (b) 3 and 4 the even cycles of solar activity.

Print Version

Interactive Discussion 

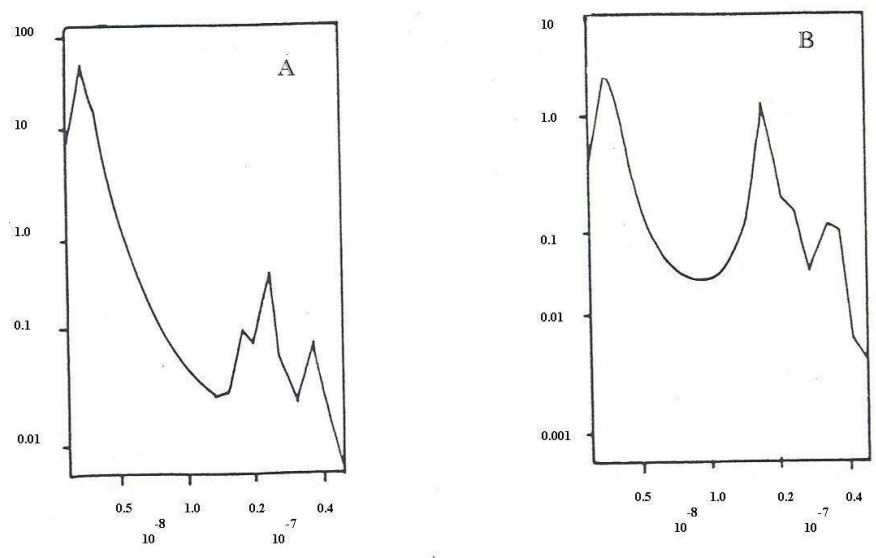

HESSD

2, 605-637, 2005

\section{Influence of solar activity on hydrological processes}

J. Pérez-Peraza et al.
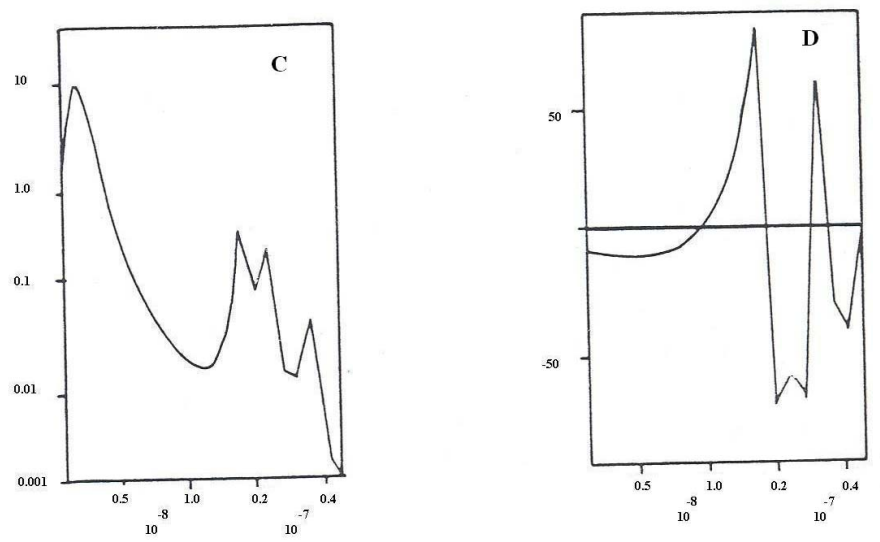

Title Page

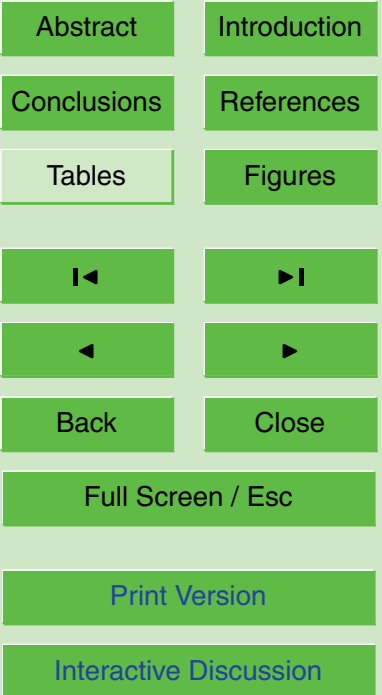

Fig. 5. Spectral characteristics of monthly values of solar activity and water level of Lake Tchudskoye for the period December 1921 to November 1932: (a) the amplitude spectrum of solar activity; (b) the amplitud spectrum of the level of Lake Tchudskoye; (c) the cross amplitude spectrum; (d) the cross phase spectrum. 

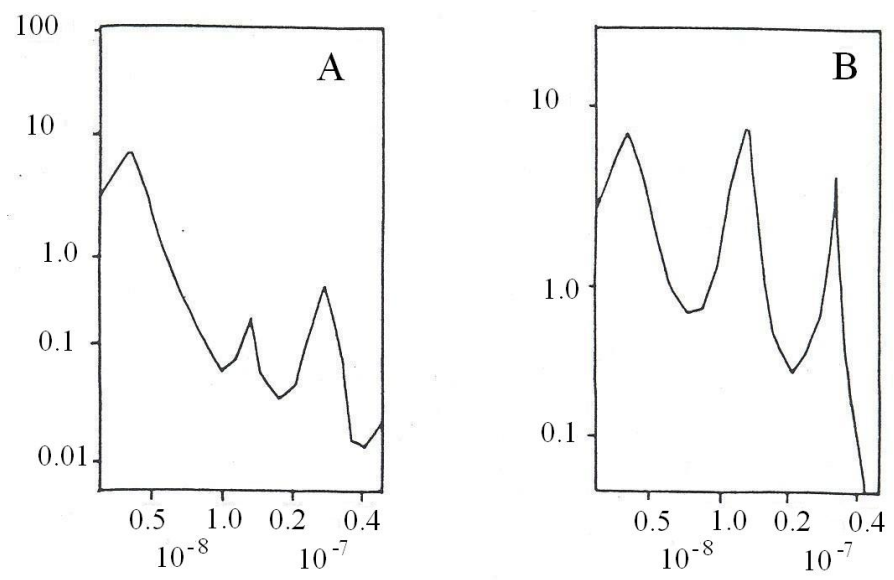

HESSD

$2,605-637,2005$

Influence of solar activity on hydrological processes

J. Pérez-Peraza et al.
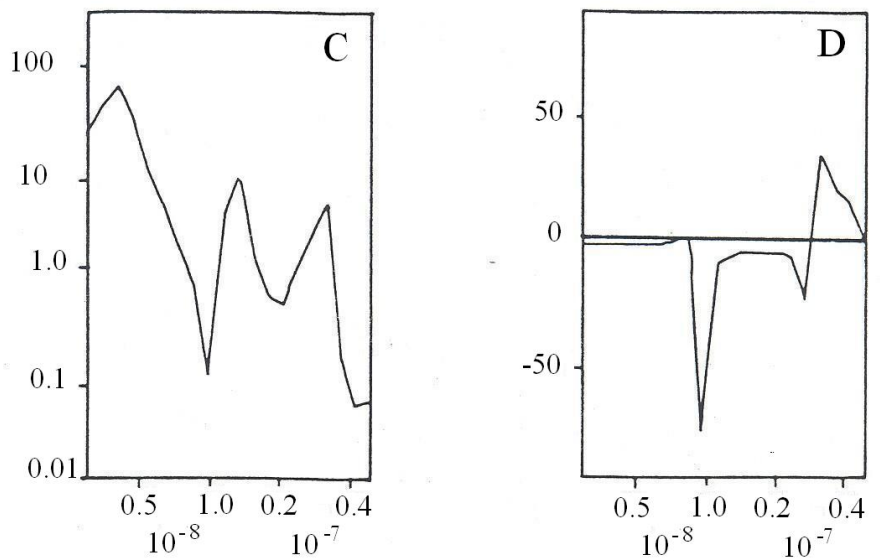

Title Page

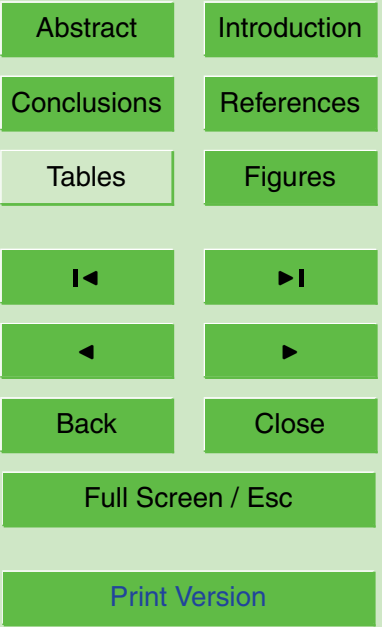

Fig. 6. The same as in Fig. 5 for the period December 1932 to May 1943. 

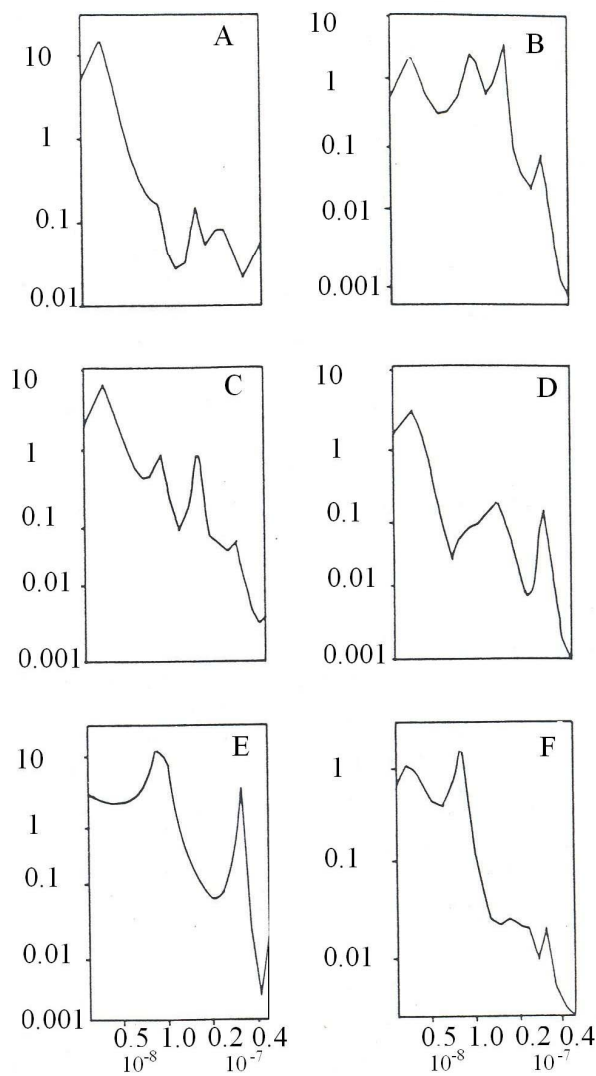

Fig. 7. Spectral characteristics of monthly values of solar activi- ty and water level of Lake Tchudskoye: (a) the amplitude spectrum of solar activity for May 1943-July 1953; (b) the amplitude spectrum of the level of Lake Tchudskoye for May 1943-July 1953; (c) the cross amplitude spectrum for May 1943-July 1953; (d) the cross amplitude spectrum for July 1953August 1963; (e) the cross amplitude spectrum for August 1963-August 1975; (f) the cross amplitude spectrum for August 1975-August 1985.

\section{HESSD}

$2,605-637,2005$

Influence of solar activity on hydrological processes

J. Pérez-Peraza et al.

Title Page

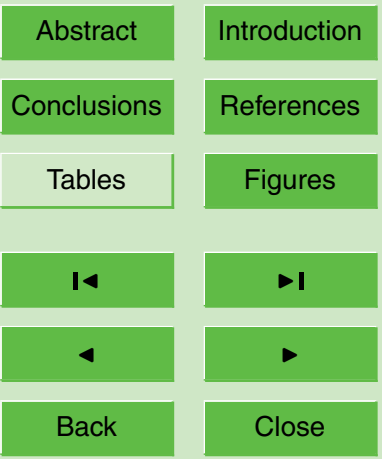

Full Screen / Esc

Print Version

Interactive Discussion 


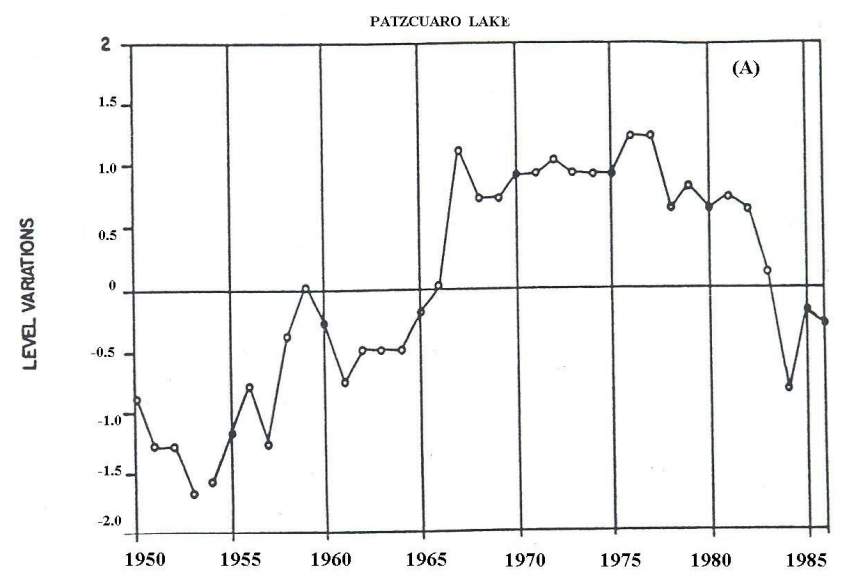

HESSD

2, 605-637, 2005

Influence of solar activity on hydrological processes

J. Pérez-Peraza et al.

Title Page

TCHUDSKOYE LAKE

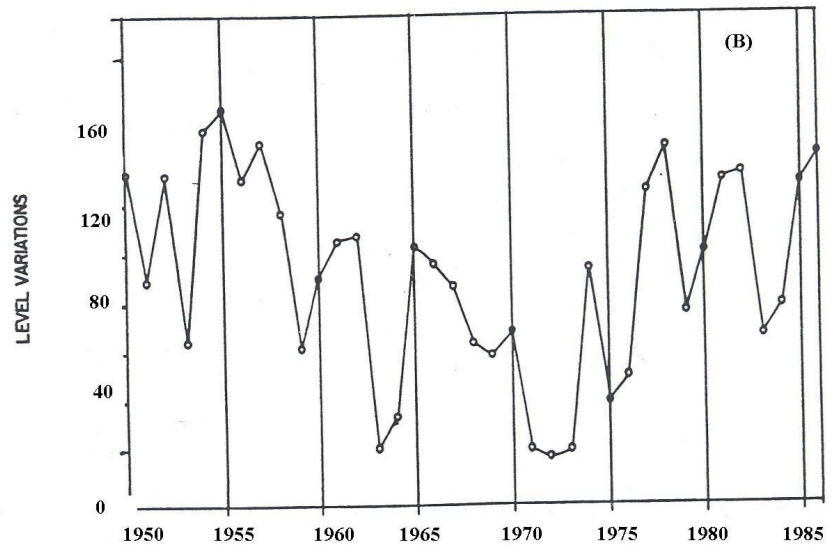

Abstract

Introduction

Conclusions

References

Tables

Figures

14

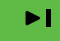

4

Back

Close

Full Screen / Esc

Print Version

Interactive Discussion

Fig. 8. Mean annual water level of lakes: (a) Lake Pátzcuaro (anomalies relative to the general 


\section{HESSD}

$2,605-637,2005$

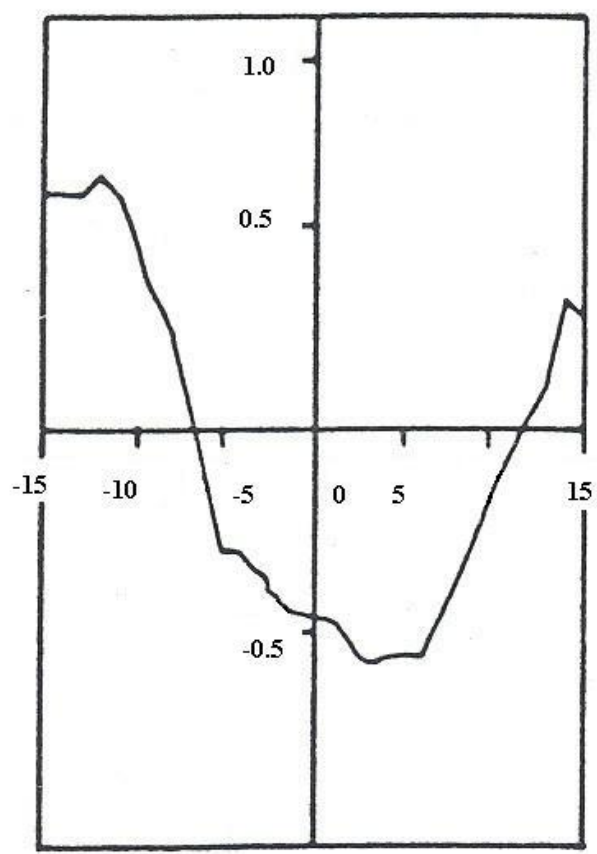

Influence of solar activity on hydrological processes

J. Pérez-Peraza et al.

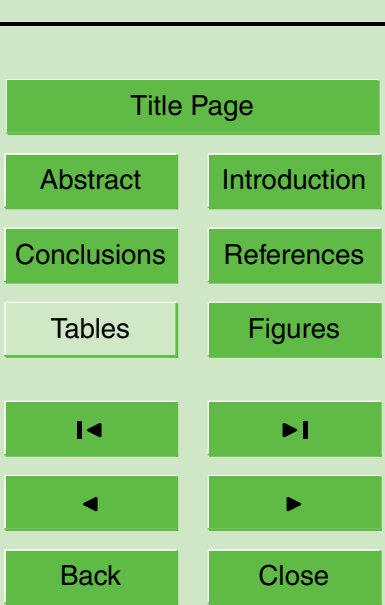

Fig. 9. Correlation function between mean annual level of Lake Pátzcuaro and that of Lake

Full Screen / Esc Tchudskoye.

Print Version

Interactive Discussion 

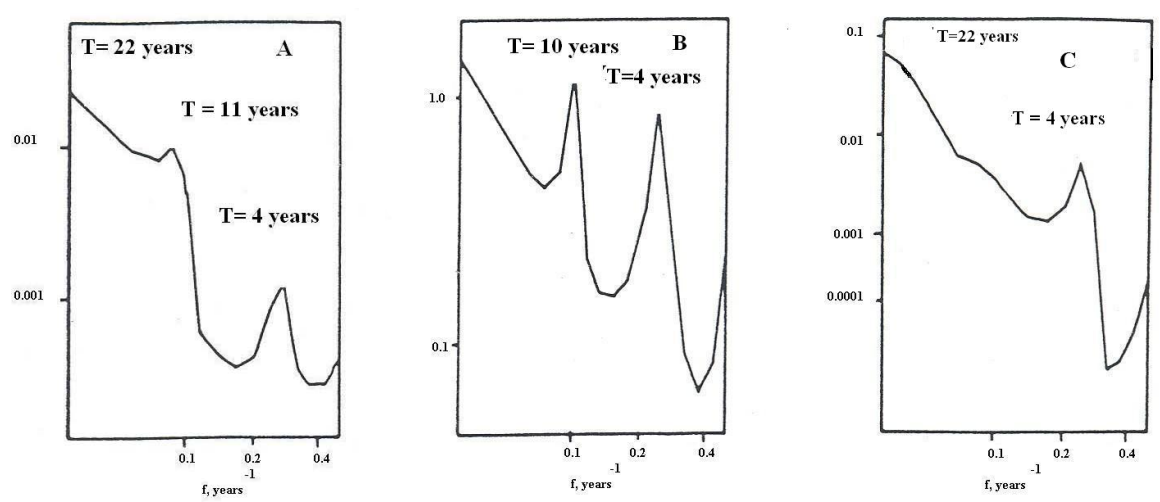

\section{HESSD}

2, 605-637, 2005

\section{Influence of solar activity on hydrological processes}

J. Pérez-Peraza et al.
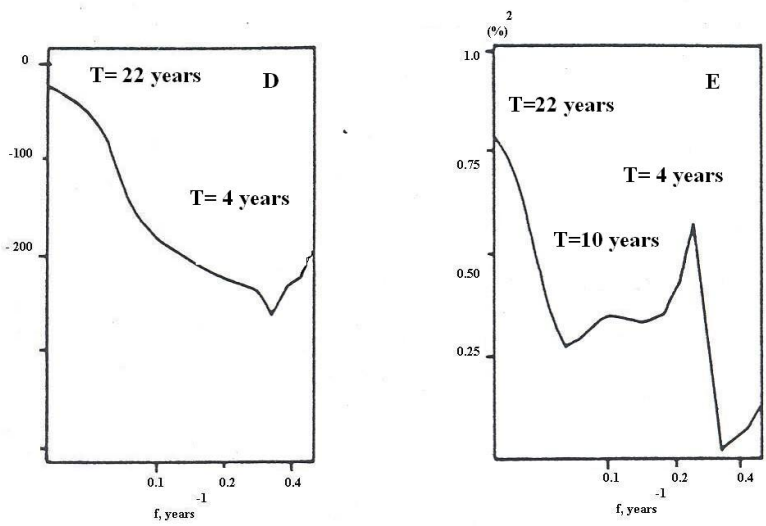

Title Page

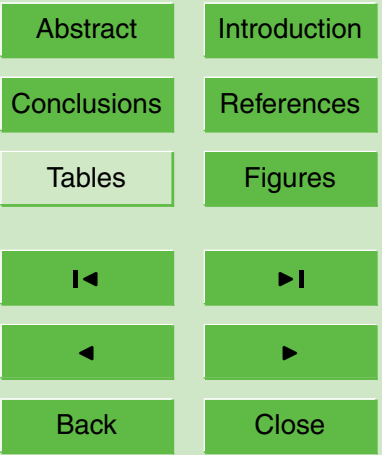

Full Screen / Esc

Fig. 10. Autorregressive analysis of the mean annual level of both lakes: (a) the amplitude spectrum of Lake Patzcuaro; (b) the amplitude spectrum of Lake Tchudskoye; (c) the cross amplitude spectrum; (d) the cross phase spectrum; (e) the cross coherence spectrum.
Print Version

Interactive Discussion 


\section{HESSD}

2, 605-637, 2005

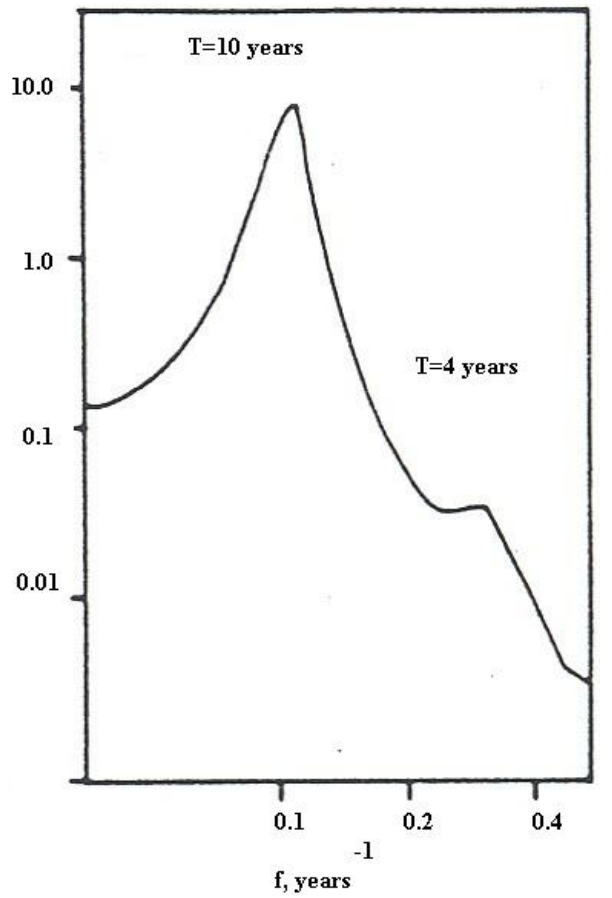

Influence of solar activity on hydrological processes

J. Pérez-Peraza et al.

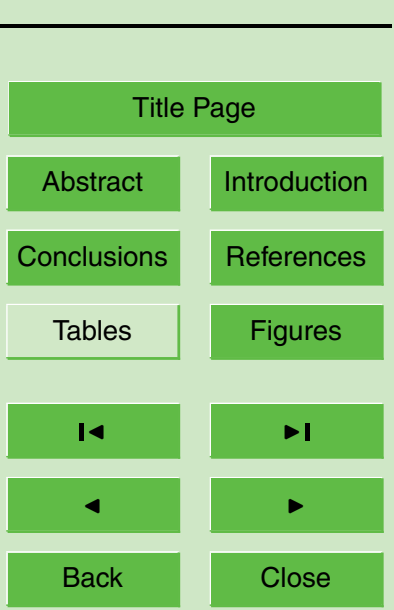

Fig. 11. The amplitude spectrum of the mean annual values of solar activity for the period

Full Screen / Esc 1950-1985.

Print Version

Interactive Discussion 

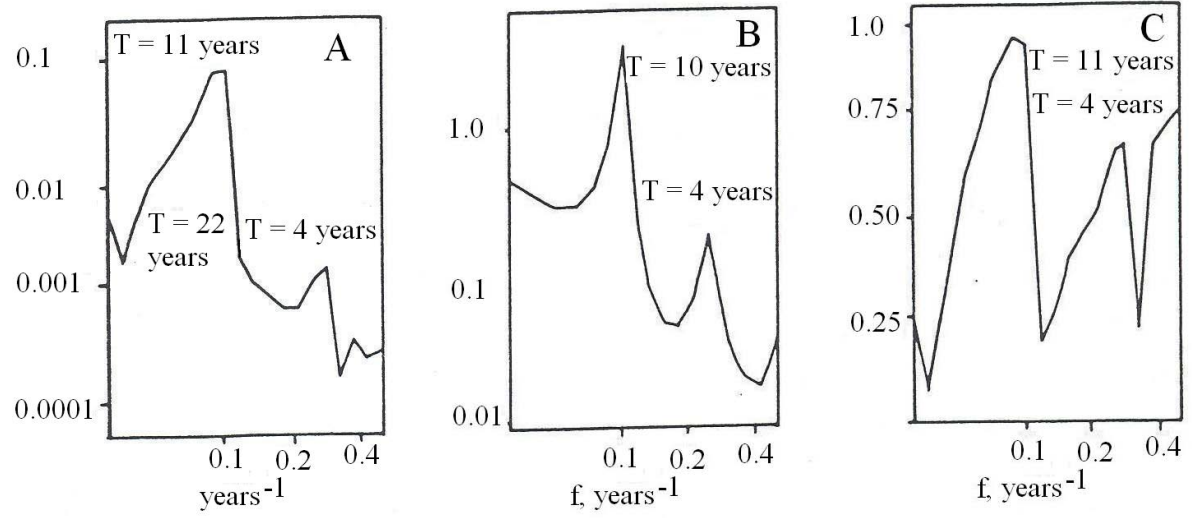

HESSD

$2,605-637,2005$
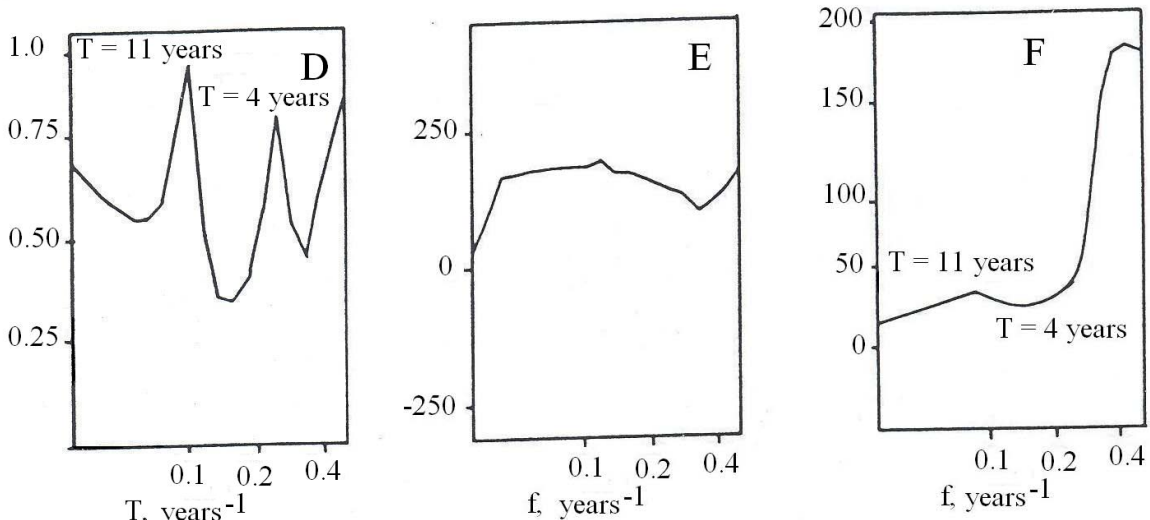

Title Page

Influence of solar activity on hydrological processes

J. Pérez-Peraza et al.

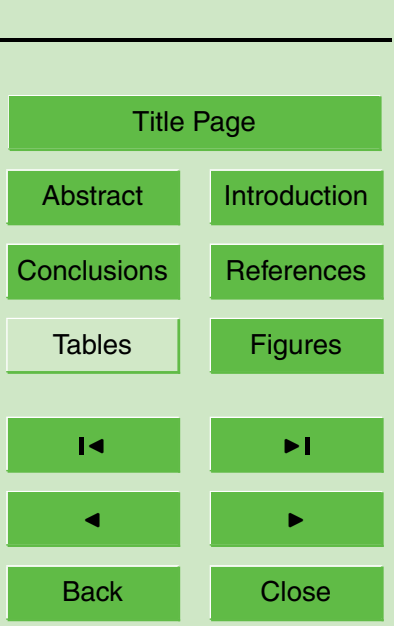

Full Screen / Esc

Fig. 12. Results of the cross autorregressive spectral analysis of solar activity (SA), Lake Patzcuaro (LP) and Lake Tchudskoye: (a) the cross amplitude spectrum LP-SA; (b) the cross amplitude spectrum LT-SA; (c) the cross coherence spectrum LP-SA; (d) the cross coherence Print Version spectrum LT-SA; (e) the cross phase spectrum LP-SA; (f) the cross phase spectrum LT-SA. 